\title{
Das Menschenrecht auf Wasser als Allokationsproblem
}

Versorgungsgerechtigkeit als institutionenökonomisches Konzept zur Umsetzung des Anliegens im Rahmen einer nachhaltigen Trinkwasserwirtschaft

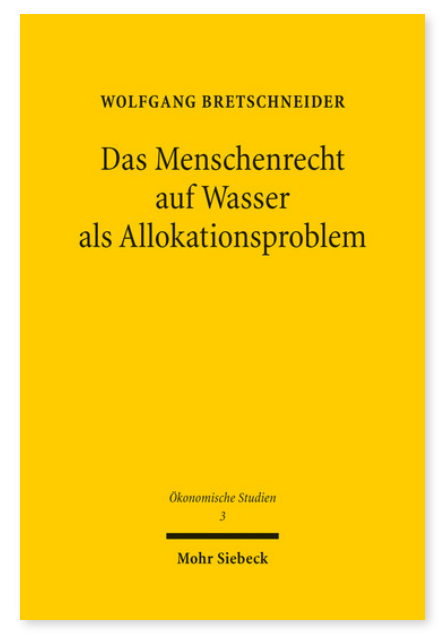

2017. XVIII, 288 Seiten. ÖkonSt 3

ISBN 978-3-16-155543-5

DOI 10.1628/978-3-16-155543-5

eBook PDF $69,00 €$

ISBN 978-3-16-155299-1

fadengeheftete Broschur 69,00€
Wie gelingt die Umsetzung eines Menschenrechts auf Wasser? Sie gelingt nur, wenn eine Trinkwasserpolitik zugleich auch in ökologischer und ökonomischer Hinsicht nachhaltig ist. Wolfgang Bretschneider skizziert auf dieser Grundlage einen institutionenökonomisch geprägten Begriff der Versorgungsgerechtigkeit, mit dem ein Spannungsfeld beschrieben wird. Denn ein privater Haushalt ist in seiner Wassernutzung nicht nur Träger eines Anspruchs, sondern umgekehrt auch Träger von Verantwortung gegenüber Umwelt und Gesellschaft. Nur wenn dies berücksichtigt wird, ist auch seine eigene Wasserversorgung langfristig gesichert. Im Zentrum des Buchs steht daher eine Konturierung des »schmalen Grats « zwischen Nutzungsanspruch und -verantwortung, die gerade auch auf Fragen des Wasserpreises angewandt wird. Zudem wird untersucht, was vor diesem Hintergrund zentrale Begriffe wie »Zugang« (zu Wasser) und affordability bedeuten und mit welchen Instrumenten die Versorgungsgerechtigkeit adressiert werden kann.

Wolfgang Bretschneider Geboren 1979; Studium der Volkswirtschaftslehre sowie Instrumentalmusik; 2016 Promotion in Volkswirtschaftslehre an der Wirtschaftswissenschaftlichen Fakultät der Universität Leipzig; seit 2016 Postdoktorand am Lehrstuhl für Wirtschaftspolitik an der Friedrich-Schiller-Universität Jena.
Jetzt bestellen:

https://mohrsiebeck.com/buch/das-menschenrecht-auf-wasser-als-allokationsproblem-9783161555435?no_cache=1 order@mohrsiebeck.com

Telefon: +49 (0)7071-923-17

Telefax: +49(0)7071-51104 